\title{
Bayesian Contractual Interpretation
}

\author{
Yair Listokin
}

\begin{abstract}
Courts seeking the most likely intent of contracting parties should interpret contracts according to Bayes's rule. The best interpretation of a contract reflects both the prior likelihood (base rate) of a pair of contracting parties having a given intention and the probability that the contract would be written as it is given that intention. If the base rate of the intention associated with the simplest reading of the contract is low, then Bayes's rule implies that the simplest reading is not necessarily the interpretation of the contract that most likely captures the intention of the parties. The Bayesian framework explains when default rules should be more or less sticky and helps to define the appropriate role of boilerplate language in contractual interpretation.
\end{abstract}

\section{INTRODUCTION}

When contracts present missing or ambiguous terms, contract law generally attempts to determine what the "parties meant" to say ${ }^{1}$ or "would have said if they had spoken about the matter" (Globe Refining Co. $v$. Landa Cotton Oil Co., 190 U.S. 540, 543 [1903]).

Determining what the parties meant to say or would have said is

YAIR LISTOKIN is Associate Professor of Law at Yale Law School. I thank Ian Ayres, Omri Ben-Shahar, Richard Brooks, Richard Craswell, Daniel Ho, Daniel Markovits, an anonymous referee, and seminar participants at the University of Michigan Law School; the University of California, Los Angeles, Law School; and the International Contracts Conference for many helpful comments and discussions. Ian Masias provided excellent research assistance. All errors are my own.

1. For expressions of this sentiment spanning 200 years of U.S. history, see, for example, Graves \& Barnewall $v$. Boston Marine Ins. Co. (6 U.S. 419, 433 [1805]), which states that "a policy is a contract of indemnity, and that what the parties meant at the time ought to be carried into effect," and Harris v. The Epoch Group, L.C. (357 F.3d 822, 825 [8th Cir. 2004]), which states that "this is simply a matter of straightforward contract interpretation. The only issue, therefore, is what the parties meant when they said."

[Journal of Legal Studies, vol. 39 (June 2010)]

(C) 2010 by The University of Chicago. All rights reserved. 0047-2530/2010/3902-0010\$10.00 
often difficult (Scott and Kraus 2007). It is therefore no surprise that contract law consists of a multitude of doctrines, decisions, and theories concerning the appropriate way to uncover the hypothetical or actual bargain of the parties. Sometimes these decisions appear counterintuitive. In the celebrated case of Jacob and Youngs v. Kent (129 N.E. 889, 891 [1921]), for example, Justice Benjamin Cardozo claims to seek the "reasonable and probable" intent of the parties with regard to the piping in a house yet appears to overlook the written insistence of the parties on the use of Reading brand pipe specifically and instead allows an alternative pipe of equivalent quality to take its place (129 N.E. 889). More generally, atypical parties have an extremely difficult time obtaining their often explicit bargain in the presence of contract law's establishment of doctrines for recreating hypothetical bargains (Goetz and Scott 1985).

This paper argues that Bayes's rule provides a useful lens for examining how contract law recreates bargains. Nearly unmentioned in prior scholarly work on contractual gap filling and interpretation, Bayes's rule provides a mathematical framework explaining how a decision maker should modify existing beliefs about a bargain between two parties in light of the evidence provided by a written contract. The modified belief about the hypothetical bargain should equal the probability that the contract would be written as it is given a particular bargain, multiplied by the prior belief about the likelihood of that bargain, divided by the total likelihood of the contract's being written as it is given any true bargain.

Consider Jacob and Youngs v. Kent from a Bayesian perspective. Suppose that there are two avenues whereby the contract language calling specifically for Reading brand pipe might have been generated. On one hand, the language fits naturally if the parties truly intended to use Reading brand pipe. Alternatively, the parties may have meant merely to use pipe of Reading quality but inartfully drafted a contract that seems to insist on the use of Reading brand pipe. It is therefore more likely that the language in the contract would have been observed if the parties desired Reading brand pipe than if they simply desired pipe of Reading quality. So, at first glance, the most likely hypothetical bargain would seem to be Reading brand pipe, although this intuition is a reflection of the base-rate fallacy.

Interpreting the contract to mean Reading brand pipe because it is the most natural reading of the contract presents an instance of the baserate fallacy (Kahneman and Tversky 1973, 1985), a common cognitive 
bias in which the decision maker underweights the prior likelihood of parties wanting Reading brand pipe (that is, the base rate) relative to the (written) evidence directly at hand. Suppose that there are many more parties in the population who prefer pipe of Reading quality rather than Reading brand pipe. This means that when confronted with a contract that specifically calls for Reading pipe, it may be more likely that the contract stemmed from parties who wanted pipe of Reading quality (high prior) and drafted their contract poorly rather than from parties who wanted Reading brand pipe (low prior) and drafted their contract well. If this is the case, then the most likely bargain between the parties is pipe of Reading quality, in spite of the fact that the contract calls for Reading brand pipe.

Bayes's rule also explains why courts may be reluctant to respect the explicit opt-out language of parties seeking to alter a default rule. Previous scholarship has critiqued this preference for default rules over explicit language as a result of judicial misunderstanding (Goetz and Scott 1985), but the preference for default rules may reflect an implicitly Bayesian approach to contract interpretation. If default rules are majoritarian, then default terms have a higher prior likelihood than do alternative terms. Language seeking to switch to the alternative term must overcome the prior weighting toward the default. If the alternative term has a low prior, then it may be extremely difficult to alter default rules through explicit language. This difficulty does not stem from any judicial misunderstanding but, rather, from the courts' application of Bayes's rule.

Similarly, Bayes's rule explains how boilerplate contractual language may be sometimes disregarded and sometimes observed. Language that is not specified by either party provides little evidence to shift prior beliefs about the likelihood of certain intentions. As a result, prior beliefs may be given more weight in the presence of boilerplate language than they would if specific bargaining for language had occurred.

The paper proceeds as follows. Section 2 examines the law and economics of contractual interpretation and gap filling. Section 3 describes Bayesian contractual interpretation and provides examples of its application to Jacob and Youngs v. Kent and Peevyhouse v. Garland Coal and Mining Co. Section 3 also discusses how Bayes's rule should be modified when judges make errors in calculating base rates and interpreting the natural reading of the contract. Section 4 applies the Bayesian contractual interpretation framework to illuminate the status of idio- 
syncratic parties and the devaluation of boilerplate language. Section 5 concludes.

\section{THE LAW AND ECONOMICS OF CONTRACTUAL INTERPRETATION AND GAP FILLING}

Law and economics scholars have devoted considerable attention to the best means of filling contractual gaps. Historically, courts aimed to provide majoritarian default rules or standards, filling gaps to provide what the parties would most likely have wanted had they considered an issue (Scott and Kraus 2007, pp. 93-95). Scholars justified this aim by explaining that it reduces transaction costs. If the state fills in gaps that the contracting pair would have wanted, then most parties will not have to undertake the expense of writing contracts that are more detailed. ${ }^{4}$

Analysis of gap filling shares many similarities with examination of standards of interpretation of written contracts (Posner 2004). In interpretation, as in gap filling, the traditional legal norm is to implement what the parties meant. In interpretation, judges simply have more information than they do when gap filling. In both cases, however, the information fails to unambiguously point to one ruling.

Despite these similarities, relatively few scholars draw an explicit link between gap filling and interpretation. ${ }^{5}$ Goetz and Scott (1985) explain how default rules contaminate the interpretation of seemingly explicit written terms. Shavell (2006) examines both gap filling and interpretation in a single framework but assumes that contracts contain either gaps or unambiguous writings of varying specificity; courts are able to distinguish between these possibilities and are free to either interpret unambiguous writings as written or choose an alternative interpretation. Moreover, Shavellian contracts contain no accidental terms or meanings. Instead, all terms derive from explicit consideration of the parties, although a court may choose to interpret a contract against the parties' meaning.

This paper departs from the existing literature in two primary directions. First, the paper assumes that contractual gaps and ambiguities are

4. For a recent summary of this explanation, along with a critical review, see Schwartz and Scott (2003, pp. 595-96). In the past 20 years, scholars have frequently articulated alternative goals for gap filling, such as facilitation of information sharing by the contracting parties. See, for example, Ayres and Gertner (1989); Bebchuk and Shavell (1991).

5. Exceptions include Posner (1998), Goetz and Scott (1985), Shavell (2006), and Schwartz and Watson (2009). 
parts of a continuum rather than different modes of analysis. A contract almost always provides some clue about what the parties might have wished in unnamed scenarios, even if it does not explicitly detail the actions associated with the scenario. ${ }^{6}$ Likewise, even the most specific and explicit instruction may contain ambiguity if it does not result from explicit bargaining between parties but, rather, represents boilerplate language. As a result, the paper applies one uniform analysis to gap filling and interpretation, which are often treated as distinct problems. ${ }^{7}$

A second distinction between this paper and previous literature is that this paper assumes that courts seek to ascertain and implement the true intentions of the contractual parties. Most of the existing literature, by contrast, assumes that courts should (and do) aim to maximize social welfare. $^{8}$

This emphasis on the recovery of a hypothetical bargain is a conditional one. The argument is not that determining what the parties would have wanted is the correct goal of contract interpretation. Instead, the aim is to examine the implications of the hypothetical bargain approach, taking as a given that the hypothetical bargain approach is the mode of interpretation. As a practical matter, many (perhaps most) courts strive to implement what the parties intended. Whatever courts' reasons for preferring to interpret contract under the hypothetical bargain context, ${ }^{9}$ the fact is that they do. Papers examining contractual interpretation from a social welfare perspective may therefore have little relevance to courts with different maximands.

The hypothetical bargain approach conditionally adopted here corresponds to the social-welfare-maximizing approach if contracting parties are ignorant of the law and do not change their drafting behavior or the quality of their performance in response to interpretative rules. In this case, a Kaldor-Hicks social-welfare-maximizing court seeks to

6. In the default rule literature, these clues correspond to the degree of tailoring to use while gap filling. See Ayres and Gertner (1989).

7. For example, one prominent contracts casebook lists four primary functions of contract law, two of which are gap filling and interpretation. See Scott and Kraus (2007, pp. 2-6).

8. An exception to this trend is Posner (1998), which also assumes that courts are seeking to give the parties what they wanted.

9. A detailed examination of why courts interpret contracts to give the parties what they wanted is beyond the scope of this paper. The hypothetical bargain context makes most sense under a corrective justice theory of contract (see, for example, Bridgeman 2007), under which parties are entitled to have their intended interpretation enforced because that is the only interpretation to which they truly agreed. 
maximize the welfare of the parties at hand. In the absence of other information available to the court (such as information regarding changed circumstances), the hypothetical bargain of the parties represents the best evidence regarding a welfare-maximizing distribution between the two parties.

\section{BAYESIAN CONTRACTUAL INTERPRETATION}

\subsection{Combining Pieces of Evidence Regarding Contractual Intent}

Consider the decision of a court interpreting a contract with two possible meanings. The court interprets the contract to actualize the most likely intention of the parties, but the court is uncertain regarding which of the two possible intentions the parties actually meant or would have meant.

The court uses two pieces of evidence to interpret the disputed term. First, the court reads the written contract itself. The written terms may be more likely to result from one intent or another. Thus, the written contract provides evidence about the true intent of the parties.

The second piece of evidence available to the court is its background knowledge of the prior likelihood (the base rate) that any pair of contracting parties have one possible intent relative to the other possible intent. This evidence depends on the existing knowledge of the court and is independent of the written contract.

Bayes's rule describes how a court should combine these two pieces of evidence to arrive at the most likely intent of the parties. The court should multiply the probability that the written contract would be written the way it is, given that the parties desired the first intent, by the prior probability that any two parties would have that intention. If the product of these two probabilities is greater than the product of the same operation for the second possible intent, then the court should interpret the contract as calling for the first intention. ${ }^{10}$

A robust empirical literature documents the base-rate fallacy-that is, the tendency of individuals to overweight the value of new evidence

10. Formally, let $P\left(B=b_{i} \mid W\right)=\left[P\left(W \mid B=b_{i}\right) \times P\left(B=b_{i}\right)\right] / P(W)$, where $B$ is the true intent of the parties, $W$ is the written document, and $b_{i}$ is the $i$ th possible intent. The term $P\left(B=b_{i} \mid W\right)$ is the probability of the true intent being $b_{i}$ given (that is, conditional on) $W$. The term $P\left(W \mid B=b_{i}\right)$ is the probability of getting $W$ given that the true intent is $b_{i}$. The term $P\left(B=b_{i}\right)$ is the unconditional probability that a bargain would be for $b_{i}$. Finally, $P(W)$ is the unconditional probability of finding $W$. 
(such as the written contract) and underweight the value of prior probabilities when making judgments (Kahneman and Tversky 1973, 1985). As a result, judges (and those evaluating the quality of judicial rulings) are likely to overweight the relevance of written contracts and underweight outside evidence when seeking to determine the true intent of the parties. Bayes's rule, however, demonstrates that if the natural reading of a contract suggests an intention that is extremely unusual within the population of contracting parties, then the meaning associated with the natural reading may be less likely to be the true meaning than an unnatural reading associated with the more common preference.

It is useful to note that conventional gap filling represents one extreme of this Bayesian interpretative format. If a written contract does not provide any evidence in favor of one meaning relative to another, then the court chooses a meaning based entirely on the prior probability of one intent or the other. The court chooses the intent that is the more likely meaning of any two parties that contract-a majoritarian default rule.

\subsection{Illustrating Bayesian Contractual Interpretation in Case Law}

3.2.1. Jacob and Youngs v. Kent. To illustrate Bayesian contractual interpretation, consider the celebrated case of Jacob and Youngs $v$. Kent (129 N.E. 889 [1921]). ${ }^{11}$ In Jacob and Youngs $v$. Kent, the New York Court of Appeals was presented with a contract between a builder, Jacob and Youngs, and a landowner, Kent, who hired Jacob and Youngs to build a home. The contract stipulated that "all wrought iron pipe must be well galvanized, lap welded pipe of the grade known as standard pipe of Reading manufacture" and included a perfect-tender condition stating that "any work furnished by the Contractor, the material or workmanship of which is defective or which is not fully in accordance with the drawings and specifications, in every respect, will be rejected and is to be immediately torn down, removed and remade or replaced in accordance with the drawings and specifications, whenever discovered."

While Jacob and Youngs was building the home for Kent, it used some pipe that was not manufactured by Reading. The pipe that was used-Cohoes brand pipe-was of similar quality to Reading. Kent's architect directed Jacob and Youngs to "do the work anew," knock down the home and install Reading brand pipe. Jacob and Youngs refused to

11. For a recent examination of this case criticizing the majority opinion, see Schwartz and Scott (2008). 
Table 1. Contracting Parties by Intention and Contractual Language

\begin{tabular}{|c|c|c|c|}
\hline Intention & $\begin{array}{c}\text { Specifies Reading } \\
\text { Manufacture and } \\
\text { Perfect Tender }\end{array}$ & $\begin{array}{l}\text { Emphasizes Pipe } \\
\text { Quality Rather } \\
\text { than Manufacturer }\end{array}$ & Total \\
\hline Reading brand pipe & 5 & 0 & 5 \\
\hline Pipe of Reading quality & 10 & 185 & 195 \\
\hline Total & 15 & 185 & 200 \\
\hline
\end{tabular}

do so. When Kent declined to pay a final balance, Jacob and Youngs sued Kent. Kent claimed that the final payment was not required because of the failure to install Reading pipe.

In Jacob and Youngs $v$. Kent, the court was required to interpret the written language concerning Reading manufacture. Did "Reading manufacture" indicate that the parties specifically meant Reading brand pipe, or did the parties mean pipe of Reading quality? Alternatively, the court was required to infer the intended remedy of the parties in the event that pipe of Reading quality but non-Reading manufacture was used. As written by Justice Cardozo, the majority opinion of the New York Court of Appeals concluded that the parties truly intended to demand pipe of Reading quality. The Cohoes pipe constituted substantial performance, leaving Kent with only nominal damages for the lack of Reading brand pipe. A forceful dissent by Justice Chester McLaughlin emphasized that Jacob and Youngs failed to perform its written obligation to provide pipe of Reading manufacture.

In the Bayesian framework, the Court of Appeals sought the most likely meaning of the contract given the contract as written and the background knowledge of the court regarding the likelihood that parties would mean to specify a specific brand of pipe.

The words "Reading manufacture" are more likely to be used if the parties specifically intended Reading brand pipe rather than pipe of Reading quality. Why use the language "Reading manufacture" and demand perfect tender if the intention of the parties was only to use pipe of Reading quality?

To quantify this intuition (see Table 1), suppose that there are 200 builder-landowner pairs. All contracting pairs (five [100 percent] of five pairs) who want Reading brand pipe choose a contract that specifies Reading manufacture, whereas only 10 (5.1 percent) of 195 pairs of contracting parties who care about pipe quality would write a contract 
calling for Reading manufacture. ${ }^{12}$ Although there is some chance that the words "Reading manufacture" meant Reading quality but the contract was inaccurately drafted, parties who wanted Reading brand pipe are considerably more likely to write "Reading manufacture" than are parties who care only about Reading quality.

At this point, it may seem like the dissent has the better argument. What more does a person have to do to get Reading brand pipe? This intuition represents an instance of the base-rate fallacy, however, in which people overweight the most salient information relative to information about the underlying base probabilities of different events.

Suppose that the large majority of contracting parties who discuss piping in contracts care only about pipe quality and not pipe brand. A total of 195 (97.5 percent) of 200 builder-landowner pairs intend to specify quality when discussing pipes, whereas five ( 2.5 percent) of 200 pairs desire a particular brand of pipe, such as Reading.

A court with these pieces of information should decide which underlying intent-Reading brand pipe or pipe of Reading quality-is more likely, given that the contract specifies Reading manufacture and demands perfect tender. According to Table 1, there will be 15 contracts that call for Reading manufacture from this population of 200 builderlandowner pairs. Five of these 15 contracting pairs will want Reading brand pipe, whereas only 10 will intend to specify Reading quality. The written contract of Jacob and Youngs $v$. Kent thus has a two-thirds (10 of 15 contracting pairs) probability of being the result of a desire for Reading quality combined with poor drafting and a one-third (five of 15 contracting pairs) probability of being the result of a desire for Reading brand pipe combined with good drafting. There are more parties who desire pipe of Reading quality and express themselves unusually than there are parties who desire Reading brand pipe and express themselves naturally. A court following Bayes's rule that wants to actualize the parties' hypothetical bargain should follow the majority opinion written by Justice Cardozo and find for pipe of Reading quality.

3.2.2. Peevyhouse v. Garland Coal \& Mining Co. Bayes's rule also helps explain the controversial decision of Peevyhouse v. Garland Coal \& Mining Co. (382 P.2d 109 [Okla. 1962]). In Peevyhouse, a mining com-

12. Note that if "Reading manufacture" were used as code for wrought iron pipe (Danzig 1978), then the probability that parties who want wrought iron pipe would use the words "Reading pipe" would be higher than 2 percent. This would make the Bayesian argument in favor of Justice Cardozo's opinion even stronger. 
pany and homeowner signed a contract allowing the mining company to strip-mine on the homeowner's land. The contract contained an unusual provision providing that the mining company would fill "the pits dug on said premises." After the mining operations were finished, the homeowners requested that the mining company fulfill its contractual obligations. The mining company refused, and the homeowners sued. In a much-criticized decision (see, for example, Maute 1995; Linzer 1981), the court ruled that the damages were limited to the small reduction in the market value of the land (one possible meaning) rather than the cost of the filling work (the other possible meaning).

The Bayesian framework provides partial justification for the decision. The unconventional written terms in the contract calling for the restorative work provide strong evidence that the parties agreed to have the work done even if the costs outweighed the benefits. So why not just interpret the contract according to its plain meaning? This would be ignoring the base rate. The court in Peevyhouse seems acutely aware that "it is highly unlikely that the ordinary property owner would agree to pay $\$ 29,000$ for the construction of improvements upon his property that would increase its value only about \$300" (382 P.2d 112). In other words, the court is appealing to base rates. The unconditional probability of agreeing to such economically "unreasonable and unrealistic" (382 P. $2 \mathrm{~d} 112$ ) behavior is minimal. Indeed, the base rate of such unreasonable behavior may be low enough to justify a holding that appears to contradict the best reading of the contract. The court is saying that it is more likely that the parties chose terms poorly but did not want economically irrational restorative work done than it is that they wrote the contract well and wanted the work done under any circumstance.

This is not to say that the Peevyhouse ruling is unambiguously correct. Suppose that there is a third possible meaning, wherein the parties agree to do restorative work that costs up to five times as much as it adds to land value. Such an agreement might still be unusual within the population. However, it is less unusual than the probability that the parties would have intended restorative work that costs almost 100 times more than it adds to market value. Indeed, when combined with the written language of the contract, which makes more sense if the parties agreed to spend more than the increase in market value, it may well be the case that the best Bayesian interpretation of the contract is for costs that are five times as much as the diminution in market value rather than equal to the diminution in value or the costs of restoration. An intermediate level of damages may well have 
been a better outcome in Peevyhouse than either diminution-in-value damages or cost-of-completion damages.

3.2.3. Applying Bayes's Rule When Judges Make Errors. Judicial estimates of the background probabilities of intentions and the likelihood that parties would write a certain contract given an intention are both subject to error (Schwartz and Scott 2003). Moreover, the stronger the court's belief about a given probability, the more likely it is that the belief is overestimated. For example, a court that assumes that no parties would ever specifically want Reading brand pipe may have underestimated the probability of desires for Reading brand pipe, but it cannot have overestimated them; there cannot be fewer than zero parties who want Reading brand pipe. Alternatively, a court perceiving that "Reading manufacture" could have been written only by parties who wanted Reading brand pipe may be overestimating the clarity of the language but cannot be underestimating it.

Knowing this possibility of errors, a Bayesian court should discount strong beliefs about prior probabilities or its ability to infer intentions solely from the language of the contract. An error-prone court that is certain that no parties want Reading brand pipe should instead assume that only a very small minority of parties would want Reading pipe. Error-prone Bayesian courts should almost never rely exclusively on either base rates or contractual language when making a decision about the true intentions of the parties.

\section{APPLICATIONS OF BAYESIAN CONTRACTUAL INTERPRETATION}

\subsection{Idiosyncratic Parties and Contractual Language}

Bayes's rule provides a benign explanation for the surprising difficulty that idiosyncratic parties have when attempting to alter state-created implied terms. Goetz and Scott argue that this difficulty provides evidence that state-created implied terms and explicit terms written by parties function antagonistically. "[C]ourts' tendency to treat statecreated rules as presumptively fair often leads to judicial disapproval of efforts to vary standard implied terms by agreement" (Goetz and Scott 1985).

The Bayesian statutory interpretation perspective discussed above 
provides an alternative explanation for default rule stickiness. ${ }^{14}$ Suppose that most state-created default terms are majoritarian: the state aims to give most parties what they want. Further suppose that efforts to explicitly opt out of state-created implied terms are at least partially unclear. In these circumstances, a majoritarian default rule would seem difficult to change. The difficulty is not the result of some presumption that courts make regarding the default rule but, rather, the result of a Bayesian interpretation of imperfect contractual language. If the base rate of the default preferences is much higher than that of the idiosyncratic preference seemingly signaled by the contractual language, then a judge seeking to implement the intent of the parties will often be justified in choosing a less natural reading associated with a higher base rate. It will therefore appear that the court is ignoring the parties' language when the court is actually choosing the most likely intention.

Nonmajoritarian default rules, such as penalty defaults, offer a means of distinguishing between the Goetz and Scott (1985) criticism of courts' exaltation of default rules and the possibility that courts are Bayesian interpreters of contracts. If Goetz and Scott are correct that default terms obtain exalted status, then information-forcing default terms should be just as sticky as majoritarian default terms. For Bayesian courts, however, a nonmajoritarian information-forcing default should be much easier to expressly alter than a majoritarian default. The base rate of the information-forcing default is lower than that of a majoritarian default, making a Bayesian court more likely to read ambiguous terms as signaling an intent to opt out of an information-forcing default term.

\subsection{The Failure of Language as Evidence of Intent}

At this point, the reader may be wondering how idiosyncratic parties can ever get their desired provisions enforced when courts are Bayesian interpreters seeking to enforce the most likely intent. When written language gives perfect evidence of intent-when there is only one intent that could be associated with the contractual language in question, even

14. Ben-Shahar and Pottow (2006) provide a signaling explanation for default rule stickiness. They do not explain, however, why courts should be reluctant to enforce explicit occurrences of opting out from default rules once the parties have overcome the signaling problem. 
Table 2. Contracting Parties by Intention and Contractual Language When 10 Percent Want Reading Brand Pipe

\begin{tabular}{|c|c|c|c|}
\hline Intention & $\begin{array}{l}\text { Specifies Reading } \\
\text { Manufacture and } \\
\text { Perfect Tender }\end{array}$ & $\begin{array}{l}\text { Emphasizes Pipe } \\
\text { Quality Rather } \\
\text { than Manufacturer }\end{array}$ & Total \\
\hline Reading brand Pipe & 20 & 0 & 20 \\
\hline Pipe of Reading quality & 10 & 170 & 180 \\
\hline Total & 30 & 170 & 200 \\
\hline
\end{tabular}

accounting for mistakes ${ }^{15}$ - then idiosyncratic parties will always obtain their desired intention by drafting the appropriate language.

Problems arise, however, when written contractual language gives imperfect evidence of intent. In these cases, the evidence provided by contractual language may not be sufficient to overcome a strong prior against an idiosyncratic provision. Idiosyncratic parties may find it impossible to obtain enforcement for their desired provision because of imperfections in language as an intent-specification technology.

The rarer the preference, the harder it will be to provide strong enough evidence to overcome the prior belief against the preference. In Jacob and Youngs $v$. Kent, for example, if there is always at least a 5 percent chance of the language "Reading manufacture" being used by mistake, then it will be impossible to have a preference that is rarer than 5 percent enforced by Bayesian courts. If the preference for Reading brand pipe is less idiosyncratic (for example, if 20 of 200 parties have this preference; see Table 2), then, by contrast, the same imprecision in language will not prevent parties from getting a preference for pipe of Reading brand specifically enforced. ${ }^{16}$

When language provides weak evidence of intent, it will be more difficult for parties to overcome a given prior belief. A classic example is a boilerplate term that is not explicitly considered by the parties' but is included in a contract (Goetz and Scott 1985). Boilerplate terms provide weaker evidence about the parties' true intent than do identical writings for which explicit bargaining occurs, because it is easier for boilerplate terms to be included

15. Note that language may be clear on its face (that is, it may follow naturally from only one possible intention) but still may provide imperfect evidence of intent once the possibility of mistakes is introduced.

16. When 10 percent of all parties want Reading brand pipe, the revised Table 1 appears as Table 2, demonstrating that it is more likely that Reading brand pipe is the parties' true intention under these assumptions. 
Table 3. Contracting Parties by Intention and Contractual Language When There Is Explicit Bargaining

\begin{tabular}{lcccr}
\hline & $\begin{array}{c}\text { Specifies Reading } \\
\text { Manufacture and } \\
\text { Perfect Tender }\end{array}$ & $\begin{array}{c}\text { Emphasizes Pipe } \\
\text { Quality Rather } \\
\text { than Manufacturer }\end{array}$ & Total \\
\hline Reading brand Pipe & 5 & 0 & 5 \\
Pipe of Reading quality & 3 & 192 & 195 \\
\cline { 2 - 3 } Total & 8 & 192 & 200 \\
\hline
\end{tabular}

in contradiction to true intent. ${ }^{17}$ Boilerplate language is a less precise-and less expensive-intent-specification technology than original language. The probabilities in Table 1, for example, may reflect the fact that the perfecttender term in Jacob and Youngs $v$. Kent was boilerplate language. If all the relevant language in Jacob and Youngs $v$. Kent was original, then Table 1 may need to be revised as shown in Table 3, enabling a Bayesian court to rule for Kent.

In practice, the quality of the signal indicating the intent of the parties is likely a function of the cost incurred in writing the contract. Although it may be impossible to obtain enforcement of an idiosyncratic preference using inexpensive language that provides weak evidence of intent, such as boilerplate language, it will more often be possible to obtain enforcement of a strange preference with more expensive bespoke language that provides greater evidence of intent. ${ }^{18}$ As a result, idiosyncratic preferences with high surplus value may be obtainable by incurring a relatively large drafting expense. As long as even the most careful original drafting retains some imprecision about the intent of the parties, however, then it may be impossible to get extremely idiosyncratic intentions enforced by a court.

17. Morin Building Products v. Baystone Construction (717 F.2d 413 [1983]) (Posner, J.) is illustrative. The Morin court rejected an assertion that a buyer satisfaction clause in a contract (allowing the buyer to reject for any reason) applied to aesthetics because the provision was "not drafted for this contract; it was incorporated by reference to another form contract." As a result, the court was "left with more than a suspicion that the [buyer rejection] clauses in the form contract used here were not intended to cover the aesthetics" (717 F.2d 415-16).

18. Similar results apply to testing for rare diseases. Because perfect tests for rare diseases are prohibitively expensive, it may be impossible to prove the existence of a rare disease with only one test. Instead, multiple rounds of testing may be necessary to prove that an initial positive test result is not a false-positive result. See Paulos (1995). 


\section{CONCLUSIONS}

The previous sections present several variations on a theme: Bayes's rule prescribes a weighting mechanism for reaching outcomes from ambiguous contractual language and preexisting beliefs about the world (base rates). When preexisting beliefs are sufficiently strong, they justify a court in contradicting the simple reading of a contract.

In effect, Bayes's rule demonstrates that the logic of majoritarian default rules does not end with pure contractual gaps. Although it is widely accepted that courts fill gaps in contracts with the terms that would be preferred by the majority of parties, such majoritarian sentiments normally cease whenever there is no gap but only an ambiguity. In these contexts, courts focus intently on the language of the contract, seeking to find the best reading of its terms. Bayes's rule, however, establishes that the logic behind majoritarian rules persists in cases of substantial or even minimal contractual ambiguity. The majoritarian preference should weight the reading of the contract; the stronger the majoritarian preference and the weaker the information provided by the ambiguous contract, the more a court should choose a meaning that implements the meaning preferred by the majority. Failure to consider the majoritarian preference when confronted with a suggestive but somewhat ambiguous written contract represents a form of the base-rate fallacy and leads to interpretations that are unlikely to implement the parties' intentions.

The Bayesian interpretative framework can be expanded to account for goals outside of giving the parties their true intent. Future work, for example, might place greater weight on the simple language of the contract than would be justified for purposes of determining intent as an incentive for parties to draft documents more clearly.

\section{REFERENCES}

Ayres, Ian, and Robert Gertner. 1989. Filling Gaps in Incomplete Contracts: An Economic Theory of Default Rules. Yale Law Journal 99:87-130.

$\rightarrow$ Bebchuk, Lucian Arye, and Steven Shavell. 1991. Information and the Scope of Liability for Breach of Contract: The Rule of Hadley $v$ Baxendale. Journal of Law, Economics, and Organization 7:284-312.

Ben-Shahar, Omri, and John A. E. Pottow. 2006. On the Stickiness of Default Rules. Florida State Law Review 33:651-82. 
Bridgeman, Curtis. 2007. Reconciling Strict Liability with Corrective Justice in Contract Law. Fordham Law Review 75:3013-40.

Danzig, Richard. 1978. The Capability Problem in Contract Law. Mineola, N.Y.: Foundation Press.

$\rightarrow$ Goetz, Charles J., and Robert E. Scott. 1985. The Limits of Expanded Choice: An Analysis of the Interactions between Express and Implied Contract Terms. California Legal Review 73:261-322.

Kahneman, Daniel, and Amos Tversky. 1973. On The Psychology of Prediction. Psychological Review 80:237-51.

— 1985. The Evidential Impact of Base Rates. Pp. 153-60 in Judgement under Uncertainty: Heuristics and Biases, edited by Daniel Kahneman, Paul Slovic, and Amos Tversky. Cambridge: Cambridge University Press.

$\rightarrow$ Linzer, Peter. 1981. On the Amorality of Contracts Remedies-Efficiency, Equity, and the Second Restatement. Columbia Law Review 81:111-39.

Maute, Judith. 1995. Peevyhouse v. Garland Coal and Mining Co. Revisited: The Ballad of Willie and Lucille. Northwestern University Law Review 89: 1341-1429.

Paulos, John Allen. 1995. A Mathematician Reads the Newspaper. Harpswell, Maine: Anchor Publishing.

$\rightarrow$ Posner, Eric A. 1998. The Parol Evidence Rule, the Plain Meaning Rule, and the Principles of Contractual Interpretation. University of Pennsylvania Law Review 146:533-77.

Posner, Richard A. 2004. The Law and Economics of Contract Interpretation. Texas Law Review 83:1581-1614.

Schwartz, Alan, and Robert E. Scott. 2003. Contract Theory and the Limits of Contract Law. Yale Law Review 113:541-619.

$\rightarrow-$ 2008. Market Damages and the Economic Waste Fallacy. Columbia Law Review 108:1610-71.

Schwartz, Alan and Joel Watson. 2009. Describability and Contract Interpretation. Working paper. Yale Law School, New Haven, Conn.

Scott, Robert E., and Judy S. Kraus. 2007. Contract Law and Theory. 4th ed. Newark, N.J.: LexisNexis.

Shavell, Steven. 2006. On the Writing and Interpretation of Contracts. Journal of Law, Economics, and Organization 22:289-314. 